\title{
EL LENGUAJE ARTÍSTICO, LA EDUCACIÓN Y LA CREACIÓN
}

\author{
Nora Ros \\ Universidad Nacional del Centro de la Provincia de Buenos Aires, Argentina
}

A qué nos referimos cuando hablamos de Arte? "El arte y el hombre son indisociables. No hay arte sin hombre, pero quizá tampoco hombre, sin arte. Pero él, el mundo se hace más inteligible y accesible, más familiar. Es el medio de un perpetuo intercambio con lo que nos rodea, una especie de respiración del alma, bastante parecida a la física, sin la que no puede pasar nuestro cuerpo. El ser aislado o la civilización que no llegan al arte están amenazados por una secreta asfixia espiritual, por una turbación moral" ${ }^{1}$

René Huyghe

\section{INTRODUCCIÓN}

El Arte, en sus más diversas expresiones, es una actividad eminentemente social, que se hace presente en la vida cotidiana del hombre. Es un aspecto central de su vida que lo ayuda a diferenciarse del resto de los seres vivos ya que él es el único capaz de producirlo y disfrutarlo. El Arte ocupa un lugar destacado para todos, es parte de la experiencia pública, ya que a través de él se manifiesta la propia cultura.

Es sabido que el hombre posee distintos niveles de actividad, algunas de ellas están referidas a lo utilitario, otras a lo científico y otras a lo artístico. La actividad utilitaria responde en primera instancia a una necesidad de subsistencia y producción para la subsistencia. La actividad científica apunta a satisfacer una necesidad de conocimiento estricto y riguroso que debe fundamentarse y demostrarse. La actividad artística, múltiple e integradora, tiene distintas funciones en diversas culturas, épocas históricas y grupos sociales, pero quizás la más importante sea la de lograr comunión, producir armonía en la personalidad, dar placer, reflejar la vida y la realidad, reflejar conflictos internos o sociales, estructurar la moral y desarrollar la capacidad creadora, base de todo nuevo descubrimiento científico que ayuda a satisfacer y mejorar la subsistencia.

Desde una mirada actualizada podemos considerar al Arte como un lenguaje, plasmado en el objeto de arte. El objeto de arte presenta un proceso de elaboración o conformación de un objeto material que, de acuerdo a la forma que recibe, expresa y comunica el contenido espiritual de manera objetiva. El hombre por medio del objeto de arte satisface sus necesidades estéticas de conocimiento, manifiesta su ideología, su subjetividad, su visión de la realidad. El objeto de arte le permite objetivar el vínculo existente entre su personalidad, la estructura cultural de la época y el

\footnotetext{
${ }^{1}$ Huyghe; R: "El arte y el hombre” Planeta Barcelona 1977
} 
medio social al que pertenece que de alguna manera lo condiciona, pero al que puede llegar a modificar. (Stokoe, P. 1990; Terigi, F. 1998). ${ }^{2}$

Hoy en día, gracias al avance de los elementos multimediales y de comunicación, estamos rodeados de infinidad de mensajes que involucran lo artístico. Algunos de ellos son directos y de fácil lectura, pero existen muchos otros donde subyacen diversos elementos de doble lectura, donde el significado y el significante se encuentran "alejados", donde subyacen diversos elementos ideológicos complejos que es necesario analizar ya que están adheridos a valores culturales que no siempre coinciden con el tipo de sociedad que queremos. En este sentido se puede considerar al Arte como un medio específico de conocimiento, ya que nos permite conocer, analizar e interpretar, producciones estéticamente comunicables mediante los diferentes lenguajes simbólicos (corporales, sonoros, visuales, dramáticos, literarios), y es aquí, por lo tanto, donde entran en juego los procesos de enseñanza-aprendizaje.

\section{EL ARTE Y LA EDUCACIÓN}

\section{La génesis social de la conciencia individual}

L. Vygotsky, plantea, que la relación del individuo con su realidad exterior no es simplemente biológica, ya que por intermedio de la utilización de instrumentos adecuados puede extender su capacidad de acción sobre esa realidad. Entre estos instrumentos, le atribuye un lugar especial al lenguaje, que es el que permite al individuo actuar sobre la realidad a través de los otros y lo pone en contacto con el pensamiento de los demás, con la cultura, que influyen recíprocamente sobre él. De esta manera puede afirmarse que el pensamiento, como las demás funciones psíquicas superiores, tienen un origen social, son la consecuencia de una relación social y no el resultado del despliegue de las posibilidades de un individuo aislado.

Para Vygotski el lenguaje es el instrumento que regula el pensamiento y la acción. El niño al asimilar las significaciones de los distintos símbolos lingüísticos que usa, su aplicación en la actividad práctica cotidiana, transforma cualitativamente su acción. El lenguaje como instrumento de comunicación se convierte en instrumento de acción.

El lenguaje, y a través de él la cultura, tienen una influencia decisiva en el desarrollo individual. El desarrollo de las conductas superiores es una consecuencia de la internalización de las pautas de relación con los demás. Por lo tanto, las posibilidades de aprendizaje pueden ser elevadas como consecuencia de la relación social. Aquí es importante diferenciar las posibilidades de aprendizaje que el niño es capaz de ejercer por sí solo, de las que podría desarrollar en un marco social adecuado, que es lo que Vigostky denomina desarrollo potencial.

\footnotetext{
2 Para ampliar esta perspectiva se recomienda: Stokoe Patricia: "Expresión Corporal. Arte, Salud y Educación". Humanitas. Bs. As. 1990 y Terigi Flavia "Reflexiones sobre el lugar de las Artes en el currículum escolar en “Artes y escuela” Paidós. Buenos Aires. 1998
} 
Tras las consideraciones realizadas desde el punto de vista vi gotskiano, creo que el problema del conocimiento debe ser contemplado atendiendo a su génesis social o sea a las influencias que tienen sobre él las relaciones sociales. Estas relaciones, se refieren sobre todo a las relaciones del mundo adulto, con la cultura adulta, capaz de proporcionar a los niños los estímulos y las enseñanzas adecuadas para el desarrollo de su pensamiento y, en general, de sus diferentes funciones psíquicas superiores. Por lo tanto, retomando la definición de Arte como lenguaje (musical, corporal, plásticovisual, oral y escrito), elemento eminentemente social, es indispensable su inclusión en el proceso de aprendizaje, ya que a través de él el pensamiento individual se apropia de la cultura del grupo humano al que se pertenece y la acrecienta.

"Conocer es construir, no reproducir. La concepción constructivista del ser humano supone la idea de que el sujeto cognitivo y social no es el mero producto del ambiente ni de la herencia, sino el resultado de un proceso dialéctico que involucra ambos aspectos. Por tanto, el conocimiento no es un reflejo del mundo sino una construcción elaborada por el sujeto en la que participan sus experiencias previas, la ideología, los saberes acumulados y las representaciones e imaginarios sociales. Cabe agregar que en esta epistemología, el acceso al conocimiento, su producción y comunicación no se limita a la palabra sino que se extiende al hacer en todas sus manifestaciones". ${ }^{3}$

\section{VALOR EDUCATIVO DEL ARTE. EL ARTE, LA CREATIVIDAD Y EL APRENDIZAJE}

En educación las artes son disciplinas tradicionales. Desde la antigüedad han ocupado un espacio relevante en lo que se considera que debe formar parte de la educación del hombre.

Sin embargo, durante mucho tiempo el Arte, a través de la Educación Artística ha ocupado un lugar periférico en los diseños curriculares en relación con otras áreas consideradas centrales. En diversos momentos se la ha tomado como un espacio dedicado al ocio, al entretenimiento; a la libre expresión de emociones y sensaciones... o a diversos intentos que le adjudicaban funciones de naturaleza terapéutica y de apoyo a las asignaturas "relevantes" a través del desarrollo de la motricidad.

Estas valorizaciones educativas se deben, en parte, a que a partir de la Modernidad la visión del Hombre y del Arte que presentó la sociedad occidental estuvo fuertemente impregnada por el pensamiento positivista.

La filosofía positivista asumió ante el conocimiento una actitud cientificista. Esta postura fomentó la idea de que el único conocimiento válido era solo aquel que podía obtenerse a través el método de las ciencias, o sea el conocimiento fáctico, empírico, observable. Esta visión, por lo tanto, relegó objetos de saber, como son los procesos psicológicos, ideológicos, culturales, sociales, que no podían ser totalmente observados ni controlados experimentalmente y por lo tanto no alcanzaban el grado de cientificidad requerido.

\footnotetext{
${ }^{3}$ Dirección General de Cultura y educación Subsecretaría de Educación Dirección de Educación Artística La Educación Artística en la E.G.B. Con Jornada Completa DOCUMENTO PARA CAPACITADORES httpl Abc.gov.ar 2002
} 
Actualmente, en nuestro país, a partir de la reforma planteada por la Ley Federal de Educación 24195 (1993), encontramos al Área Artística planteada como aquella que debe brindar a los alumnos la posibilidad de conocer los códigos de las distintas disciplinas que la integran: Música, Expresión Corporal, Plástica y Teatro (esta última si bien no se plantea explícitamente en los documentos curriculares para el Nivel Inicial, en la práctica se la utiliza permanentemente). Estos conocimientos son necesarios para acceder a las distintas experiencias creativas existentes y por lo tanto saberse capaces y con derecho a disfrutarlas y también a producirlas.

Desde una perspectiva escolar, como fundamento teórico del Área Artística, podemos tomar a la "Educación por el Arte.", teoría sustentada por Herbert Read ${ }^{4}$, que propone no hacer de todos los individuos artistas, sino acercarles los lenguajes de las disciplinas artísticas que les permitan nuevos y distintos modos de comunicación y expresión, desarrollando las competencias individuales interrelacionadas con lo social, a través de la sensibilización, la experimentación, la imaginación, y la creatividad.

En la filosofía de la Educación por el Arte no se pretende formar artistas profesionales, sino formar un pueblo que practique y disfrute actividades artísticas, hechos creativos, o sea reivindicar los lenguajes artísticos como formas estéticas de comunicación entre los hombres. (Stokoe, 1990)

El hecho creativo es el resultado de una serie de simbolizaciones, vivencias y asimilaciones de conocimientos, es una síntesis de componentes cognitivos, afectivos, sociales e imaginativos. Sin aprendizaje no hay creatividad posible.

La actividad creadora aparece entonces como una forma de relación especial, ya sea entre los niños y el adulto o de los niños entre sí, con un claro valor educativo. Pero, la actividad creadora muchas veces no es considerada en nuestro sistema educativo como una actividad apropiada para el desarrollo de los aprendizajes en el aula ya que la mayoría de las personas creen que la creatividad o la creación es un "don" privativo de algunos elegidos a los cuales se los encuadra dentro de la categoría de artistas, talentos, descubridores, genios, etc. Puede afirmarse que esto no es así y para sustentarlo me remitiré a las palabras de L. S. Vigotsky "Llamamos actividad creadora a toda realización humana creadora de algo nuevo, ya se trate de reflejos de algún objeto del mundo exterior, ya de determinadas construcciones del cerebro o del sentimiento que viven y se manifiestan sólo en el propio ser humano., ${ }^{, 5}$. Toda actividad creadora posee como base a la imaginación que se encuentra manifestada por igual en los aspectos culturales, científicos o técnicos de la vida del Hombre. Todo lo que no tenga que ver con el mundo de la naturaleza y sí con el de la cultura es el resultado de la imaginación y de la creación humana. Por lo tanto, todos los seres humanos poseemos capacidad para la creación.

\footnotetext{
${ }^{4}$ Read, Herbet : Poeta inglés, considerado como una autoridad en materia de Historia y Filosofía del Arte, ha derivado sus estudios hacia otros campos como el de la Educación, la Sociología y la Historia de la Cultura. En su libro "Arte y Educación" ( 1991) su tesis se basa en vivificar la formulada por primera vez por Platón que promueve la idea de que el arte debe ser la base de toda forma de educación natural y enaltecedora. Para ello se dedica a aclarar conceptos fundamentales: Educación y Arte y la relación de ambos con la formación durante todas las etapas evolutivas del hombre.

${ }^{5}$ Vigotsky L.S. "La imaginación y el Arte en la Infancia” Ensayo psicológico Fontamara México 1997
} 
Esto puede entenderse mejor si observamos que en la actividad del hombre, en su conducta, se distinguen dos tipos básicos de impulsos. Uno que podría llamarse reproductor o reproductivo, relacionado directamente con la memoria, ya que el ser humano tiene la capacidad de reproducir , repetir normas de conducta ya creadas y elaboradas, y de volver a vivir experiencias pasadas. Pero, si nuestro cerebro se limitara a conservar experiencias anteriores, el hombre no sería capaz de tener una reacción adaptadora ante cualquier cambio que se produjese en su medio ambiente. Sabemos que esto no es así, por lo tanto se puede decir entonces que, junto a esta función memorizadora, el cerebro posee otro impulso, otra función que es la que combina y crea.

"Toda actividad humana que no se limite a reproducir hechos o impresiones vividas, sino que cree nuevas imágenes, nuevas acciones, pertenece a la función creadora o combinadora. El cerebro no se limita a ser un órgano capaz de conservar o reproducir nuestras pasadas experiencias, es también un órgano combinador, creador... .Es la actividad creadora del hombre la que hace de él un ser proyectado hacia el futuro, un ser que contribuye a crear y que modifica su presente." 6

Durante las actividades creativas, dramatizaciones, teatros de sombras, mimos, modelados, musicalizaciones, etc. los niños reproducen mucho de lo que ven, pero no se limitan a recordar experiencias vividas, sino que las reelaboran creativamente, construyendo de esta manera, a través de distintas combinaciones, otras nuevas.

Cabe aclarar que la combinación creadora no se da natural ni repentinamente. A cada etapa evolutiva le corresponde una forma de creación que le es propia y que está directamente relacionada con la experiencia acumulada. Por eso es falso suponer que los niños poseen mayor imaginación o creatividad que los adultos. Esto se justifica simplemente por que los niños han vivido menos tiempo que los adultos y por lo tanto poseen menor cantidad de experiencias que les permitan desarrollar su creatividad.

Lo que si puede afirmarse es que la actividad creativa se relaciona directamente con la variedad y la riqueza de la experiencia acumulada. ${ }^{7}$

Así llegamos a una importante conclusión pedagógica: es necesario ampliar la experiencia del niño si queremos brindarle una sólida base para su actividad creativa.

Si el niño no conoce por una experiencia anterior elementos que le permitan inventar, no podrá crear o recrear, ya que es la combinación de estos elementos lo que constituye algo nuevo, creador, que pertenece al niño...combinar lo antiguo con lo nuevo, sienta las bases de la creación. Sería un milagro que la imaginación pudiera crear algo de la nada o dispusiera de otra fuente de conocimiento distinta de la experiencia pasada.

\footnotetext{
${ }^{6}$ Ibíd. 2

7 Vigotsky , su obra "La Imaginación y el Arte en la hfancia" al analizar la relación entre la fantasía y la realidad plantea cuatro tipo de vinculaciones: la primera marca la relación entre la experiencia acumulada y la creación, la segunda entre elementos complejos de la realidad y productos de la fantasía, la tercera corresponde al enlace emocional (los sentimientos influyen en la imaginación - la imaginación influye en los sentimientos) y la cuarta se refiere a que la fantasía puede representar algo completamente nuevo, no existente en la experiencia del hombre
} 
Como consecuencia de lo anterior llegamos a la fundamentación de la intervención docente, ya que deberán ser los maestros los responsables de brindar a sus alumnos experiencias creativas, desde el Área Artística, que sirvan de base a nuevas creaciones o a recreaciones.

\section{A MODO DE CIERRE}

Debe quedar claro que la función de la Educación Artística en el sistema educativo no consiste en la formación de artistas, para eso se encuentran las instituciones especializadas, pero si debe brindar el conocimiento de las técnicas, los recursos, los materiales y su organización, la posibilidad de expresarse y comunicarse.

Es mi convicción que a la escuela, como institución especializada en brindar educación, le cabe la tarea de desarrollar acciones que posibiliten el disfrute y la producción de Arte en sus diversas manifestaciones.

Debe ofrecer a los alumnos la oportunidad de conocer y aprender los distintos lenguajes artísticos, como lenguajes alternativos. El aprendizaje de los lenguajes artísticos, implica el conocimiento de sus facetas sintácticas, semánticas y pragmáticas. Este tipo de conocimiento contribuirá a alcanzar competencias complejas relacionadas al desarrollo de la capacidad de abstracción, a la construcción de un pensamiento crítico y divergente y a la apropiación de valores culturales. Por lo tanto, apropiarse de estos conocimientos permitirá a los alumnos, realizar su propia elaboración y producción de expresiones artísticas, además de capacitarlos para apreciar las producciones de los demás, sean estas las de sus compañeros o las de artistas del pasado, del presente, del ámbito local o del contexto mundial.

El arte no es sólo técnica, es historia,

es lenguaje de una época y cultura,

El arte no es patrimonio sólo de un hombre,

es patrimonio de la humanidad

\section{BIBLIOGRAFÍA}

CALVo, Marta: "La Educación por el Arte" en Artes y escuela. Cap.7. Buenos Aires Paidós 1998

VIGOTSKY, L.S.: "Imaginación y el arte en la infancia" (ensayo psicológico). Bs. As. Akal, 1982

HARGREAVES, D. J.: "Infancia y educación Artística". Madrid. Morata. 1991.

STOKOE, Patricia: Expresión Corporal. Arte, Salud y Educación. Buenos Aires Humanitas. 1990 


\section{Documentos}

DIRECCIÓN GENERAL DE CULTURA Y EDUCACIÓN Subsecretaría de Educación Dirección de Educación Artística: Documentos pedagógicos "Fundamentación La Educación Artística en el Sistema Educativo" http\ Abc.gov.ar 2002

DIRECCIÓN GENERAL DE CULTURA Y EDUCACIÓN Subsecretaría de Educación Dirección de Educación Artística: La Educación Artística en la E.G.B. Con Jornada Completa Documento Para Capacitadores http $\backslash$ Abc.gov.ar 2002

DIRECCIÓN DE EDUCACIÓN ARTíSTICA: "Acerca de DEA Documento Curricular Jornada Completa Inicial, EGB, Especial, Polimodal” Escuelas de Educación Estética Nivel Medio Terciario No Universitario Documento Curricular B-1 Fundamentos y Propósitos del Área . http Abc.gov.ar 2002

DiRECCIÓN General de Planeamiento Dirección de Currícula. Aportes para el desarrollo Curricular Educación Inicial 2002. 


\title{
Contactar
}

Revista lberoamericana de Educación

\author{
Principal OEI
}

